\title{
Highlighting the importance of medical research: School of Medicine medical student research program
}

\author{
Gurvinder Kaur PhD, Jannette M. Dufour PhD
}

\begin{abstract}
Research into human physiology and causes of disease is necessary to provide cutting edge medical treatment. As a cart is useless with only one wheel, similarly medicine alone without research is not sufficient to advance techniques and knowledge. Research is the driving force behind development of new drugs, techniques, or discovery of new pathways. Physicians play a critical role not only in the discovery of new treatments but also to advance these newly discovered drugs or techniques as they enter clinical trials where the efficacy and safety of these advancements are tested. A new discovery can take anywhere from 5-20 years on average before it is moved from bench to bedside and launched into the market for the benefit of the general public. Research requires the perseverance and determination to stay focused on the end goal.
\end{abstract}

The discovery of life saving technologies such as dialysis for patients with renal failure buys time until a perfect match is located for kidney transplantation. This was not the scenario in the early 1930s when physicians took the lead to save the lives of their patients. A physician, Willem Kolff, felt helpless when several of his young patients died due to renal failure. ${ }^{1}$ Rather than just providing palliative care to these critically ill patients, he wanted to do more. Therefore, he took the matter into his own hands and developed a new way to filter the blood. With perseverance and determination, he developed the first dialysis unit using sausage casings and the motor of a sewing machine in 1943. Ten years later, another physician, Jean Hamburger, performed a living donor human kidney transplant. ${ }^{2} \mathrm{~A} 16$-year-old patient received a kidney from his mother. However, the kidney stopped working after 22 days post-transplantation.

Corresponding author: Jannette Dufour Contact Information: Jannette.dufour@ttuhsc.edu DOI: 10.12746/swrccc.v7i29.550
Joseph Murray, after studying renal transplantation in dogs, performed the first successful long-term kidney transplantation between monozygotic twins in 1954. The transplanted organ survived for 8 years, and in 1990 Murray was honored with the Nobel Prize in physiology or medicine for his work. ${ }^{3}$ These examples highlight the importance of the work performed by pioneering physicians in advancing medical treatment.

Current medical treatments are based on scientifically proven evidence, so it is important to not only appreciate the value of research but also to make a conscious effort to keep up with the cutting edge research that is constantly improving medicine and the quality of care provided to patients.

The Texas Tech University Health Sciences Center (TTUHSC) School of Medicine (SOM) created a summer research program in $2010^{4}$ to highlight the importance of research and give students a hands on experience of the hard work, patience, and determination necessary for successful research. This is an eight-week program during the summer between years 1 and 2 of medical school that provides an opportunity for medical students to gain research experience. During this program, medical students are paid to work with mentors of their choice on basic science, clinical, or educational research projects. At the end of the summer students have the option to continue to work with their mentors during the second year of medical school. Since the program was created, 520 students have participated, and the percent of students who reported participation in research at graduation for the Association of American Medical Colleges (AAMC) Medical Student Graduate Questionnaire has increased from $55.1 \%$ in 2010 to $78.8 \%$ in $2018 .{ }^{4}$

Previous students who have participated in this program indicated that this experience has strengthened their critical thinking skills and increased their understanding of the pathophysiology behind disease that allows them to better treat and educate their future patients. Past students also indicated that this 
experience heightened their problem solving skills and encouraged them to be inquisitive. In addition, students mentioned that it was very rewarding to be able to spend their summer getting firsthand exposure to the trials and tribulations of research. For example, learning about how dysfunctional cell signaling pathways contribute to the induction, maintenance, and progression of disease, students also gained a much greater appreciation for how much time and effort goes into every journal article publication.

Students who participate in this program have the opportunity to present their results at the TTUHSC Student Research Week (SRW). This issue of the Southwest Respiratory and Critical Care Chronicles highlights abstracts presented at the TTUHSC SRW in March 2019 by medical students who participated in the SOM summer research program during the summer of 2018 .

While not all medical students will continue to pursue research, this program provides a valuable opportunity for them to gain initial research experiences. In the future, this will improve their critical thinking skills and give them the foundation of knowledge necessary to practice current evidence-based medicine. For those who continue to pursue research, perhaps they will be like those pioneering individuals described above and discover the innovative scientific breakthroughs that will lead to future groundbreaking medical treatments.
Keywords: medical students, research, medical education, summer elective

Article citation: Kaur G, Dufour JM. Highlighting the importance of medical research: School of Medicine medical student research program. The Southwest Respiratory and Critical Care Chronicles 2019;7(29):1-2 From: The Departments of Medical Education (KG) and Cell Biology and Biochemistry (JMD) in the School of Medicine at Texas Tech University Health Sciences Center in Lubbock, Texas

Submitted: 4/22/2019

Conflicts of interest: none This work is licensed under a Creative Commons Attribution-ShareAlike 4.0 International License.

\section{REFERENCES}

1. Henderson LW. A tribute to Willem Johan Kolff, M.D., 19122009. J Amer Society Nephrology 2009;20(5):923-924.

2. Hatzinger M, Stastny M, Grützmacher P, et al. The history of kidney transplantation. Urologe A 2016;55(10):1353-1359.

3. Snyder A. Joseph E Murray. The Lancet 2013;381(9861):110.

4. Kaur G, Dufour JM. An update on the School of Medicine's Medical Student Research Program at Texas Tech University Health Sciences Center. The Southwest Respiratory and Critical Care Chronicles. 2018,6(24):1. 